\title{
The effect of water deficit on inflorescence period at palm oil productivity on peatland
}

\author{
Nanik Ambar Suharyanti ${ }^{1}$, Kosuke Mizuno ${ }^{1 *}$, and Ahyahudin Sodri ${ }^{1}$ \\ ${ }^{1}$ School of Environmental Science, Universitas Indonesia, Central Jakarta, 10430, Indonesia
}

\begin{abstract}
Various factors influence palm oil production, including planting material, environment (climate and soil), and cultivation management. The environment occupies a crucial position that can affect crop production potential even with optimal cultivation management. Unfavorable climatic conditions, for instance, drought, can cause water deficit, which has implications for crop productivity. This paper aims to get a comparative study for the effect of water deficit on the inflorescence period, namely the sex determination phase ( 29 months before harvesting) and floral abortion (10 months before harvesting). The research was carried out on oil palm plantations on peatland in Riau, Indonesia, with the characteristic annual rainfall of $2000 \mathrm{~mm} /$ year. This study employs a simple regression analysis on panel data of five years and two estates for data analysis. The result highlights that the increase of a $100 \mathrm{~mm}$ water deficit on oil palm peatland plantation impacts the decrease in productivity by $6 \%$ in the sex determination phase. In contrast, in the floral abortion phase, the decline in productivity is more significant, namely $7 \%$. The analysis also indicated that the research deficit had more impact on the bunch number than the bunch weight.
\end{abstract}

\section{Introduction}

Oil palm productivity is a synergy between genetic factors (planting material) and the environment [1-3]. In achieving the sustainability of the palm oil industry, productivity is a crucial factor, so that it requires a detailed understanding of the factors that influence it [4-5]. Technologically, planting material and soil is relatively easy to engineer or process, while climate needs a detailed and in-depth study of natural phenomena. Climate is posited as a crucial factor in its influence on oil palm productivity [6-9]. Several previous researchers have made studies on these interactions, including [2, 8]. The study [2] states four levels of plant productivity, with each factor playing a role at each level (shown in Figure1). [8] describes a productivity scheme divided into three stages with each influencing factor (shown in Figure 2). Both researchers stated that plant material and the environment (climate and soil) are crucial factors that support productivity because they are positioned at the initial level before cultivation management factors.

\footnotetext{
* Corresponding author: kosuke.mizuno@ui.ac.id
} 


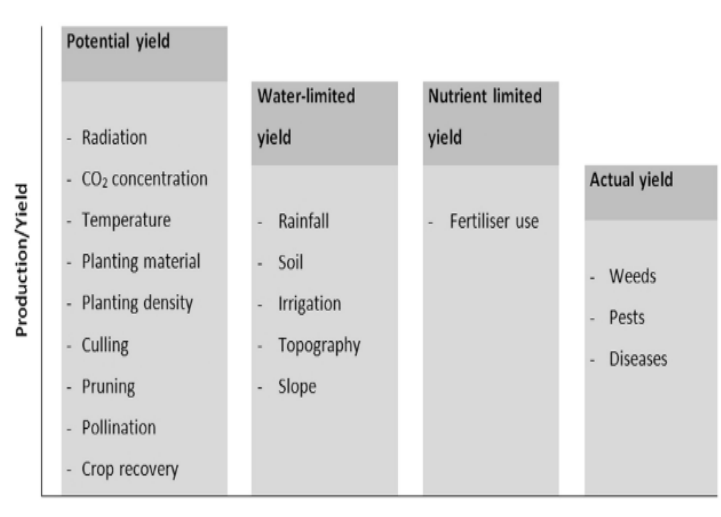

Fig. 1. Differences in the level of oil palm production and its factors contribute [2].

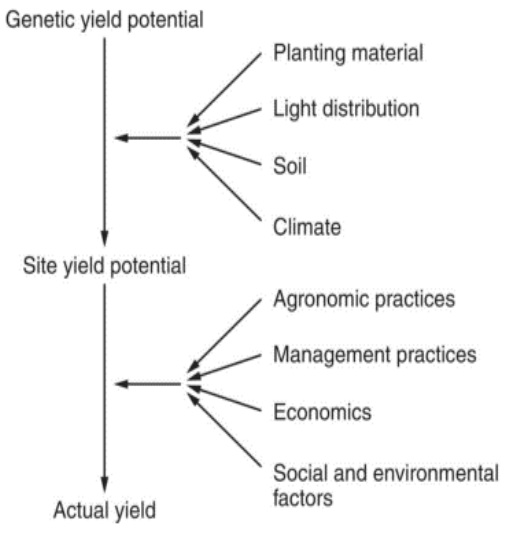

Fig. 2. Scheme definitions of factors that influence the potential for genetic outcomes and actual results [8].

Among the agro-climatic factors, water supply is the most important for palm oil [10]. Unfavorable climatic conditions such as drought can reduce water supply to cause water deficits that affect fruit formation and yield [11]. Drought can affect oil palm productivity by reducing the number formed due to male and female flowering ratios [12]. Oil palm plants are different from other palm plants that carry male and female flowers at the same flowering; the sex determination of oil palms is determined during the flowering phase [13].

There is a time lag between the effect of environmental stress and its implications for crop production $[6,7,8,14,15]$. Several factors influencing this time lag included soil conditions and fruit development $[15,11]$. Previous studies state that an increase in water deficit of $100 \mathrm{~mm}$ in one year can decrease production by $8-10 \%$ in the first year after that and $3-4 \%$ in the second year $[10,6]$. [8] explained in more detailed that a $100 \mathrm{~mm}$ water deficit could have an impact on FFB production in the flowering phase, namely 1) floral initiation (1-3\% yield loss per $100 \mathrm{~mm}$ water deficit), 2) sex determination (3-4\% yield loss), 3) floral abortion (8-10\% yield loss). However, the study did not mention in detail the type of soil. Another study in Ghana showed that the higher the water deficit, the lower the oil palm production. The study results are described as follows a) yields ranging from 2225 tonnes/ha FFB with an annual water deficit of $150 \mathrm{~mm}$, b) 16-18 tonnes/ha FFB with an annual water deficit of $250 \mathrm{~mm}$, and c) 6-7 tonnes/ha FFB for areas with an annual water deficit of $400 \mathrm{~mm}$ [16]. Based on this, a fundamental study of plant physiology on environmental factors (water deficit) is required as a basis for drought mitigation consideration.

Thriving in tropical countries, Indonesian oil palm plantations rely heavily on rain as the primary water source. The application of irrigation techniques is still rare in oil palm plantations in Indonesia. Oil palm plants need sufficient water conditions, starting from the nursery stage, maintenance, and before harvest. Understanding the climate and its effects on oil palm growth is very important to ensure the palm oil industry's sustainability, given the increasing need for this sector.

Oil palm requires climatic conditions suitable for growth, including annual rainfall of 2000 - $3500 \mathrm{~mm}$ /year, monthly rainfall > $100 \mathrm{~mm}$, minimum water deficit, and dry spell [17-18]. Indonesia experienced an unfavorable climate phenomenon in 2015. The climate anomaly phenomenon, El Nino, has reduced rainfall and increased air temperature, 
contributing to drought stress for oil palm crops. Drought in the tropics is closely related to El Nino, where this climate anomaly can cause reduced or even no rain for a long time [18]. Water stress will increase male flower production, which underlies the decline in oil palm production $[19,11]$. This condition is a problem for oil palm plantations, especially on peatlands. Peat soil has irreversible drying properties where it will be difficult to get wet again if the soil has dried for a certain period [20]. Therefore, the water deficit problem needs to be studied so that preventive action before the critical period occurs.

The definition of water deficit is the discrepancy between field capacity and the amount of water retained in the soil at a certain period [8-9]. Water deficit in oil palm plants on peatlands can occur due to two things, namely climate anomalies and improper water management (implication of irreversible drying). A climate anomaly is an event that cannot be avoided, but it can be predicted that further mitigation actions are taken. Water deficit affects the flowering phase, especially in the sex determination and floral abortion phases $[21,6]$. If preventive efforts are carried out too late, it will impact the fruit formation process so that the fruit can experience abortion and failure to form bunches. Oil palm plants experience 4 phases of flowering starting from 1) floral initiation, 2) sex determination, 3) anthesis, 4) harvest [21, 7]. The effect of stress (including drought) on the period of plant growth is shown in Figures 3 and 4.

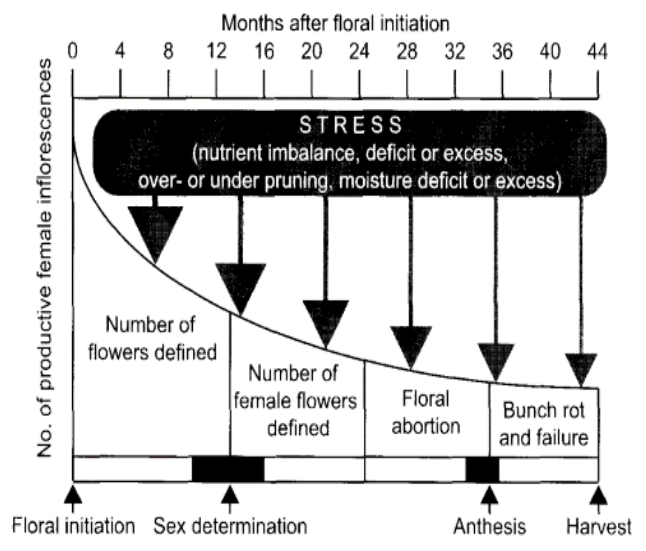

Fig. 3. Effect of stress on bunch number in oil palm to stress [7].

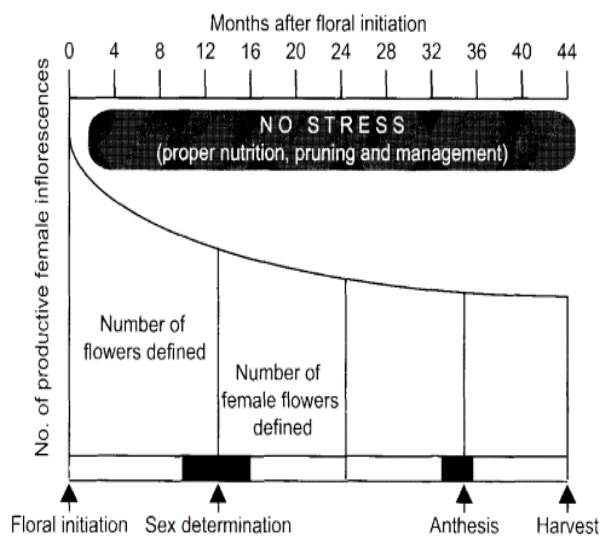

Fig. 4. Effect of eliminating stress on bunch number in oil palm to stress [7].

This study will discuss the effect of environmental factors, namely water deficit in the sex determination phase and floral abortion on the production of Oil Palm Fresh Fruit Bunch. Sex determination is the period of sex formation of fruit that occurs 29 months before harvesting, while floral abortion is the abortion of bunches, which usually occurs 910 months before harvesting. Floral abortion is the phase between sex determination and anthesis, which generally occurs 4 - 6 months before anthesis [21, 22, 23, 7, 24]. There are at least four types of factors that may participate in sex determination, namely 1) abiotic factors (e.g., water deficit), 2) metabolic factors (e.g., carbon stock), 3) hormone status and 4) genetic factors [25].

This study aims to get a comparative analysis for the effect of water deficit on the inflorescence period, namely the sex determination phase (29 months before harvesting) and floral abortion (10 months before harvesting). This paper will make a unique study on the effect of water deficit on palm oil plantations' productivity, especially peatlands. 
Peatland oil palm plantations were chosen because, as the world's biggest palm oil producer, 25\% of Indonesia's oil palm plantations are located on peatlands [26].

The research location was carried out on a peatland oil palm plantation in Riau Province, Indonesia. Marginal land, such as peat, is relatively more challenging to become cultivated land than mineral land. However, if done with proper water management, peatlands can store water longer than mineral lands. The peatlands will probably gain in the face of a lousy climate that causes drought.

\section{Method}

\subsection{Study area}

The research was conducted in a private oil palm plantation in Riau Province with a cover area is 3.109 ha and an average density of 120 stands per hectare. This research used adult palms aged 8-15 years. This study chose adult palms because it is more susceptible to drought. The effect of drought is relatively mild on young palms ( $<8$ years) and old palms (>15 years) [27]. The type of soil in the observation estate is entirely peat. The average annual rainfall is $2000 \mathrm{~mm} /$ year.

\subsection{Data collection}

This study utilizes secondary data from private oil palm plantations for production data, bunch number, and bunch weight for 2015-2019 and rainfall for 2012 - 2018. Rainfall data will be used to calculate the water deficit value.

\subsection{Meteorological data}

Drought stress analysis is carried out by calculating water deficit, using variable climate components, namely rainfall, rainy days, and evapotranspiration [25]. The annual water deficits are calculated following [21] based on the method of the Institut de Recherches pour les Huiles et Oléagineux (IRHO) with Equation 1.

$$
B=\operatorname{Res}+R-E t p
$$

$\mathrm{B}$ is the balance at the end of the period, Res is the soil water reserve at the start of the period, and $\mathrm{R}$ and Etp are the rainfall and potential evapotranspiration during the period.

\subsection{Data analysis}

This research employs a quantitative approach with simple regression analysis on five years' panel data and two estates for data analysis. Simple regression analysis was chosen to find out how independent variables affect the dependent variable [28]. This study determined the water deficit in the sex determination period and floral abortion period as independent variables while the yield of palm oil, bunch number, and bunch weight as dependent variables. The statistical program used for data processing is Eviews 11.

\section{Results and discussion}


This research analyzes the correlation between water deficit and crop production for adult palm, including the two constituent components, namely the bunch number and average bunch weight in the efflorescence phase. The primary oil palm production components are bunch number, bunch weight, and oil content [29]. The environmental conditions strongly influence bunch numbers during inflorescence, namely sex determination and floral abortion. Bunch weight is affected by the number of fruits formed from the female flowers produced during the inflorescence phase [29]. The flowering period in mature palms generally occurs around $2-3$ years $[21,7,8,11]$. This research highlights two main phases that affect the success of inflorescence, namely sex determination and floral abortion. Sex determination is the most critical process in the development of the oil palm. The period is determined 29 months before harvesting, while the floral abortion is ten months before harvesting [21,23].

In this paper, water deficit calculation using the IRHO method is carried out per month by considering the rainfall, rainy days, and evapotranspiration per month. Following the IRHO method [21], water balance is the sum of monthly rainfall plus water reserves at the beginning of the month, minus evapotranspiration per month. At the beginning of the month, the water reserve comes from the previous month's water reserve or a maximum $200 \mathrm{~mm}$ value. Evapotranspiration is assumed to be $150 \mathrm{~mm} / \mathrm{month}$ if the rainy day is $\leq 10$ days per month or $120 \mathrm{~mm} /$ month if the rainy day is $>10$ days/month. The water balance value shows the availability of water per month. If the water balance is $<0 \mathrm{~mm}$, there is a water deficit; if the water balance is more than $200 \mathrm{~mm}$, the excess water will be stored by the soil and used for the following month (the maximum value of water reserve and held by the ground is $200 \mathrm{~mm}$ ).

This study analyzed secondary data on two private oil palm plantations located in Riau Province and calculates the water deficit value. The calculation results are shown in Figure 5 while simultaneously displaying rainfall and plant productivity to determine their harmony. Plant productivity in January 2015 is compared with rain and water deficit in the sex determination phase (29 months before harvesting) or in August 2012 and so on the following month. Meanwhile, the analysis results in the floral abortion phase (10 months before harvesting) are shown in Figure 6. In the floral abortion period, productivity in January 2015 is compared to rainfall and water deficit in March 2014, and continue in the following months.

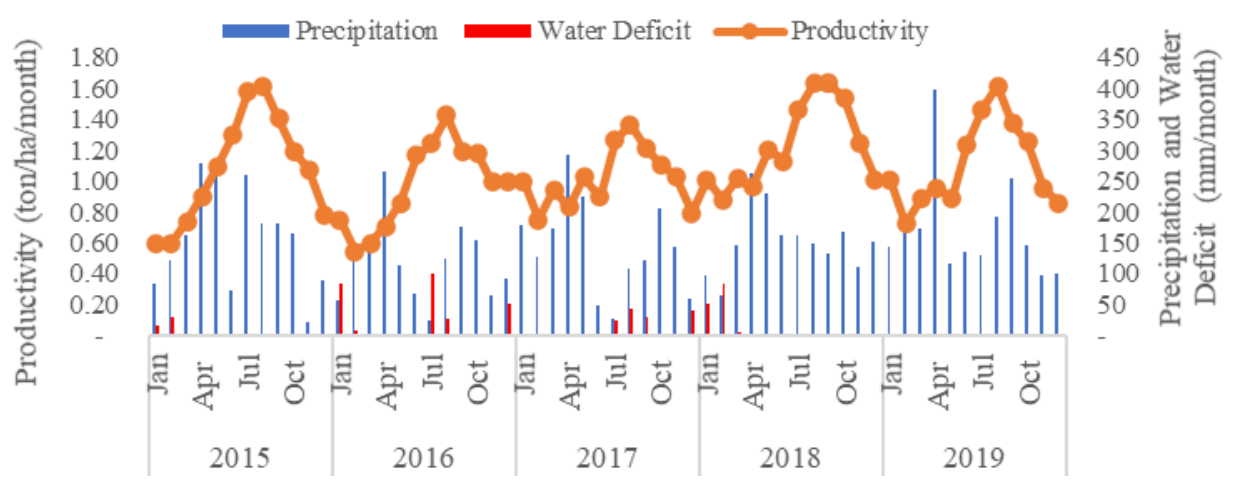

Fig. 5. The pattern of productivity distribution of palm oil with precipitation and water deficit in the sex determination phase (Source: Author's Analysis, 2020). 
Figure 5 and Figure 6 show the relationship between rainfall, water deficit, and plant productivity. Oil palm plants' productivity will increase if accompanied by sufficient water conditions through adequate rain for the plants, so that a minimum water deficit. Assessment of water adequacy in oil palm plants through water deficit calculations shows that the distribution of monthly precipitation over a year is essential in the water balance of oil palm plants [30]. Oil palm, an originate tropical forest plant in West Africa, requires evenly distributed rainfall per month (there is no dry month, namely precipitation $<100 \mathrm{~mm}$ per month) [31].
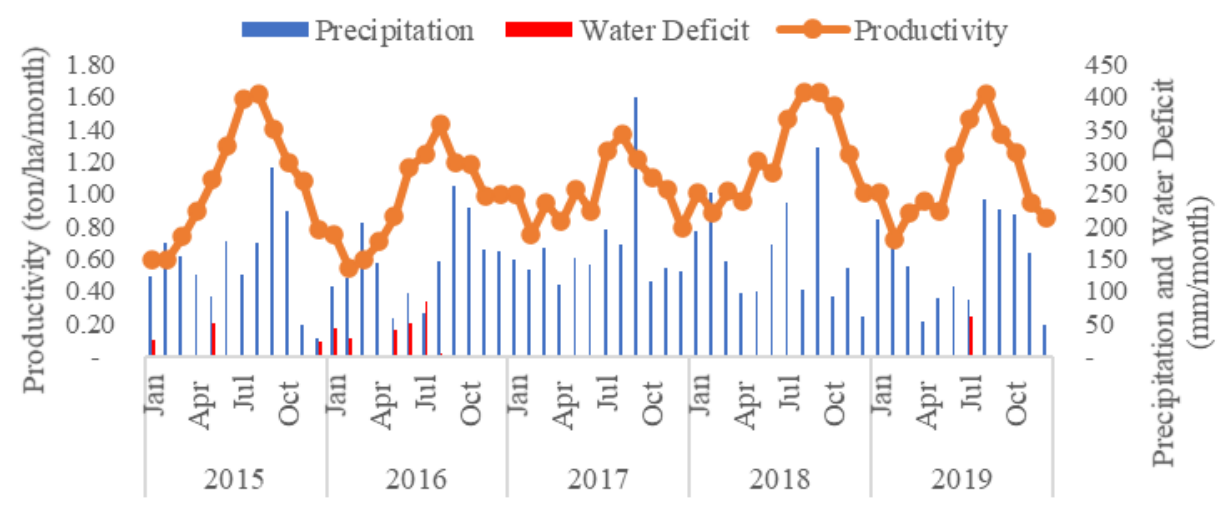

Fig. 6. The pattern of production distribution of palm oil with precipitation and water deficit in the floral abortion phase (Source: Author's Analysis, 2020).

The productivity of oil palm plants is determined by the number of female flowers in the flowering phase. To determine the effect in detail, this research conducted a statistical test by correlating the relationship between water deficit in two critical stages of flowering to three components: plant productivity, bunch number, and bunch weight. The analysis results are shown in Table 1.

Table 1. Relationship of the effect of water deficit on the inflorescence period.

\begin{tabular}{ccccc}
\hline \multirow{2}{*}{ Variable } & \multicolumn{3}{c}{ Water Deficit on The Inflorescence Period } \\
\cline { 2 - 5 } & \multicolumn{2}{c}{ Sex determination } & \multicolumn{2}{c}{ Floral Abortion } \\
\cline { 2 - 5 } & c & coefficient & c & coefficient \\
\hline Yield (ton/ha/annum) & 14,27 & $-0.008074^{*}$ & 13,93 & $-0.009184^{*}$ \\
\hline $\begin{array}{c}\text { Bunch Number } \\
\text { (bunch/plant) }\end{array}$ & 11,85 & $-0.008783^{*}$ & 11,17 & $-0.004030 \mathrm{~ns}$ \\
\hline $\begin{array}{c}\text { Bunch Weight } \\
\text { (kg/bunch) }\end{array}$ & 9,59 & $+0.006067^{*}$ & 10,26 & $-0.001753 \mathrm{~ns}$ \\
\hline Significance level of effects: $n$
\end{tabular}

Significance level of effects: n.s., not significant; * significant $(\mathrm{p}<10 \%)$.

\subsection{Water deficit and palm oil production}

Based on the analysis result (Table 1), water deficit in sex determination and floral abortion phases significantly affected plant yield $(\mathrm{p}<10 \%)$. The floral abortion phase's coefficient value is greater than that of the sex determination phase, which means that the floral 
abortion phase's effect will have a more significant impact than that of the sex determination phase. Water deficit in the floral abortion phase will reduce productivity by $7 \%$ for every $100 \mathrm{~mm}$ increase in water deficit. In comparison, the water deficit in the sex determination phase will reduce productivity by $6 \%$ for every $100 \mathrm{~mm}$ increase in water deficit.

Water deficit can reduce oil palm productivity through low sex ratio and floral abortion [21]. The higher the sex ratio, the more female flowers. The low sex ratio occurs because the sex determination period is disturbed so that more male flowers are formed than female flowers, which will develop into a fruit. However, a high sex ratio does not fully guarantee high productivity [32]. This case is due to the possibility of abortion of female flowers and the failure of bunches. Flower abortion occurs due to a lack of carbohydrates for flower development, water deficit, and over-pruning to stress the plant [21, 32]. Based on the research results, the decrease in productivity in the floral abortion phase in peatlands is smaller than the previous research results (without specifying the type of land), which states that productivity decreases by $10 \%$ [6]. This research presume that the decline in oil palm productivity on peatlands (with proper water management) due to water deficit has a smaller value than mineral soils. Because, with proper water management, peatlands can store more water than mineral lands. This assumption is in line with research from [13], which states that the abortion of oil palm bunches is much smaller (2-13\%) on deep peatlands in Malaysia with proper water management.

\subsection{Water deficit and bunch number}

Bunch number dramatically affects the production of oil palm plants. Previous studies stated that the bunch number was more correlated with crop production than weight [33]. Therefore, the critical point in the bunch formation period needs to be considered to reduce yield losses. The number of a bunch per stand is primarily influenced by sex determination during the development of the inflorescences. That process occurs about 29 months before the maturity of fruit in mature palms [21, 11]. Previous researchers stated that the variation in the formation of the bunch number is determined by three mechanisms: changes in the rate of development of flowers, variations in the sex of flowering, and abortion flowering in the flowering period [33]. [13] adding another factor that also influences, namely, bunches failure between anthesis and harvest.

The results of the analysis in Table 1 show that the water deficit has significant implications $(\mathrm{p}<10 \%)$ for the variable bunch weight in the sex determination phase. In contrast, in the floral abortion phase, the effect is not significant. The sex determination phase determines the sex of flowers in which sufficient water conditions will tend to form more female flowers than male flowers. This female flower will then develop into a fruit to be harvested. Therefore, the sex determination phase influences the amount of fruit that will be produced by plants.

\subsection{Water deficit and bunch weight}

Several components contribute to the formation of mature oil palm bunches, including the number of spikelets, the number of flowers per spikelet, the percentage fruit set, the mean weight per fruit, and the frame [8]. Among these components, the number of spikelets and the number of flowers per spikelet are formed in the flowering phase, strongly influenced by water availability.

The statistical analysis in Table 1 shows that the water deficit has only significant implications in the sex determination phase. Water deficit affects the increase in bunch weight, but only with a low percentage of $6 \%$. 


\subsection{Production projection based on precipitation and water deficit}

Physiologically, oil palm plants need adequate water conditions to support their growth. Knowledge of this critical point of drought stress is required to determine the pattern of oil palm production so that projections can be made for the next year and mitigation measures to minimize the percentage decline in production.

The production-distribution pattern is essential by planters to determine the production target in the next production year. Planters must try to take mitigation measures, for instance, by applying optimal fertilizers and maintaining soil moisture with ground cover crops to minimize stress to plants. Knowledge of water deficit can also be used as a consideration for irrigation in plantations. However, the application of this irrigation technology is not yet famous for oil palm plantations in Indonesia. Empirical data on Thailand Oil palm Plantations states that daily drip irrigation during the dry season can increase productivity by up to $50 \%$ [34].

\section{Conclusion}

Water deficit in the inflorescence period affects decreasing oil palm production on peatlands. An increase in water deficit by $100 \mathrm{~mm}$ in the sex determination phase will reduce productivity by $6 \%$ while in the floral abortion phase, decreasing $7 \%$. Knowledge of the impact of water deficit on the efflorescence phase is useful for knowing the oil palm production pattern to predict future production. Besides, planters can also take mitigation measures to decline output is not too significant. Such mitigation measures are, for instance, by optimizing fertilization to avoid nutrient imbalances and also by maintaining soil moisture with cover crop plants. This paper contributes to the study of oil palm plantation management by providing evidence of the effect of water deficits in the inflorescence period at oil palm productivity on peatlands. For oil palm plantations on peatlands, drought mitigation can be pursued with proper water management. This researh indicate that the water deficit's effect on oil palm plantations on peatlands with appropriate water management is not as significant as on oil palm plantations on mineral lands. Therefore, it is necessary to carry out further research to be a comparison with this research. Another thing that also needs to be studied in further research is the water deficit on young palms and old palms to compare adult palms' impact.

\section{Acknowledgements}

This study was supported by Universitas Indonesia, with grant number NKB 2577/UN2.RST/HKP.05.00/2020.

\section{References}

1. N. N Kamil, S. F. Omar, The impact of el niño and la niña on malaysian palm oil industry, Oil Palm Bulletin 74, 1 (2017)

2. L. S. Woittiez, M. T. van Wijk, M. Slingerland, M. van Noordwijk, K. E. Giller, Yield gaps in oil palm: a quantitative review of contributing factors, European Journal of Agronomy 83, 57 (2017) https://www.doi.org/10.1016/j.eja.2016.11.002

3. C. xu Sun, H. xing Cao, H. bo Shao, X. tao Lei, Y. Xiao, Growth and physiological responses to water and nutrient stress in oil palm, African Journal od Biotechnology 10, 10465 (2011) https://www.doi.org/10.5897/ajb11.463

4. A. Ibragimov, S. F. Sidique, Y. S. Tey, Productivity for sustainable growth in 
Malaysian oil palm production: A system dynamics modeling approach, Journal of Cleaner Production 213, 1051 (2019) https://www.doi.org/10.1016/j.jclepro.2018.12.113

5. F. Parish, J. Mathews, L. S. Yan, M. F. Zainuddin, J. L. F. San, RSPO Manual on BMPs for Existing Oil Palm Cultivation on Peat, (2019)

6. M. K. V. Carr, The water relations and irrigation requirements of oil palm (Elaeis guineensis): a review, Experiment Agriculture 47, 629 (2011)

https://www/doi.org/10.1017/S0014479711000494

7. T. Fairhurst, W. Griffiths, Oil Palm: Best Management Practices for Yield Intensification (Parkway Lane, 2014)

8. R. H. V. Corley, P. B. Tinker, The Oil Palm: Fifth Edition. John Wiley and Sons (2015)

9. M. Culman, C. M. de Farias, C. Bayona, J. D. Cabrera Cruz, Using agrometeorological data to assist irrigation management in oil palm crops: a decision support method and results from crop model simulation, Agricultural Water Management 213, 1047 (2019) https://doi.org/10.1016/j.agwat.2018.09.052

10. J. P. Caliman, A. Southworth, Effect of drought and haze on the performance of oil palm, International Oil Palm Conference, 23-25 September 1998, Bali, Indonesia (1998)

11. N. Tani et al., Small temperature variations are a key regulator of reproductive growth and assimilate storage in oil palm (Elaeis guineensis), Scientific Reports 10, 1 (2020) https://www.doi.org/10.1038/s41598-019-57170-8

12. R. H. V. Corley, V. Rao, T. Palat, T. Praiwan, Breeding for drought tolerance in oil palm, Journal of Oil Palm Research. 30, 26 (2018) https://www.doi.org/10.21894/jopr.2017.00011

13. L. S. Woittiez, On yield gaps and better management practices in Indonesian smallholder oil palm plantation, Theses. Wageningen University (2019)

14. P. Oettli, S. K. Behera, T. Yamagata, Climate based predictability of oil palm tree yield in Malaysia, Scientific Reports 8, 2271 (2018)https://www.doi.org/10.1038/s41598018-20298-0

15. A. E. Eycott et al., Resilience of ecological functions to drought in an oil palm agroecosystem, Environmental Research Communications 1, 101 (2019) https://www.doi.org/10.1088/2515-7620/ab48da

16. T. Rhebergen, T. Fairhurst, K. E. Giller, S. Zingore, The influence of water and nutrient management on oil palm yield trends on a large-scale plantation in Ghana, Agricultural Water Management 221, 377 (2019) https://www.doi.org/10.1016/j.agwat.2019.05.003

17. S. Paramananthan, Land Selection for Oil Palm in Oil Palm: Management for Large and Sustainable Yields Eds. (Dakota, 2003)

18. T. S. Najihah, M. H. Ibrahim, A. A. Razak, R. Nulit, P. E. W. Megat, Effects of water stress on the growth, physiology and biochemical properties of oil palm seedlings, AIMS Agriculture and Food 4, 854 (2019) https://www.doi.org/10.3934/agrfood.2019.4.854

19. M. Speight and P. Henderson, Marine Ecology : Concepts and Applications (New York, 2010)

20. J. Andriesse, Nature and Management of Tropical Peat Soils. Rome: Food and Agriculture Organization (FAO) of United Nations (Rome, 1988)

21. C. W. S. Hartley, The Oil Palm (Elaeis guineensis Jacq.). -3rd. ed.-(Tropical agriculture series) (New York, 1988)

22. H. Adam et al., Environmental regulation of sex determination in oil palm: current knowledge and insights from other species, Annals of Botany 108, 1529 https://www.doi.org/10.1093/aob/mcr151.

23. Y. K. Keong, W. M. Keng, Statistical modeling of weather-based yield forecasting for young mature oil palm, APCBEE Procedia 4, 58 (2012) 
https://www.doi.org/10.1016/j.apcbee.2012.11.011.

24. T. T. Tiemann et al., Feeding the palm: a review of oil palm nutrition, Advances in Agronomy 152, 149 (2018) https://www.doi.org/10.1016/bs.agron.2018.07.001.

25. I. Y. Harahap, S. Sumaryanto, T. C. Hidayat, W. R. Fauzi, Y. Pangaribuan, Production of oil palm sex inflorescense and its response on the treatment of plant exogenous hormone treatment under drought condition, Journal of Palm Oil Research 25, 31 (2017) https://www.doi.org/10.22302/iopri.jur.jpks.v25i1.23

26. R. Khatun, M. I. H. Reza, M. Moniruzzaman, Z. Yaakob, Sustainable oil palm industry: the possibilities, Renewable and Sustainable Energy Reviews 76, 608 (2017) https://doi.org/10.1016/j.rser.2017.03.077.

27. I. Y. Harahap, Winarna, E. S. Sutarta, Oil palm productivity: an overview of soil and climate aspects, Land and Oil Palm Fertilization, 246 (2010)

28. C. Kothari, Research Methodology : Methods and Techniques Second Rev. (New Delhi, 2004)

29. S. Legros, I. Mialet-Serra, J. P. Caliman, F. A. Siregar, A. Clément-Vidal, M. Dingkuhn, Phenology and growth adjustments of oil palm (Elaeis guineensis) to photoperiod and climate variability, Annals of Botany 104, 1171 https://www.doi.org/10.1093/aob/mcp214.

30. W. Darmosarkoro, I. . Harahap, E. Syamsuddin, Technical culture of oil palm plants in drought conditions and efforts to overcome it, Oil Palm Research Center 228-245 (2010)

31. A. Rival, P. Levang, Palms of Controversies: Oil Palm and Development Challenges (Bogor, 2014)

32. S. Agustiana, R. Wandri, D. Asmono, Performance of oil palm in dry sesason in South Sumatera: effect of water deficit on plant phenology, National Seminar on Suboptimal Land, 18-19 Oktober 2018, Palembang, Indonesia (2018)

33. J. C. Combres et al., Simulation of inflorescence dynamics in oil palm and estimation of environment-sensitive phenological phases: a model based analysis, Functional Plant Biology 40, 263 (2013) https://www.doi.org/10.1071/FP12133

34. T. Palat, C. Nakharin, J. H. Clendon, R. H. V. Corley, A review of 15 years of oil palm irrigation research in Southern Thailand, Planter, 84, 537 (2008) 